\title{
Mal comparando...: os efeitos argumentativos da metáfora e da analogia numa perspectiva cognitivo-discursiva
}

\author{
Solange Vereza*
}

\begin{abstract}
Resumo
Este artigo, de um modo geral, aborda a questão dos efeitos ideológicos da metáfora na produção de sentidos, sob a perspectiva da linguística cognitiva (LC), área já bastante consolidada nos estudos da linguagem. Mais especificamente, o foco recai no modo como a ideologia pode ser abordada, teórica e analiticamente, na recente vertente dos estudos da metáfora, que contempla o entrelace entre a dimensão cognitiva e a discursiva da linguagem figurada em uso. Nessa perspectiva, o objetivo do trabalho é explorar, teórica e analiticamente, o argumento de que a metáfora, assim como a analogia, tece a argumentatividade - que seria o modo pelo qual a ideologia se configura como um "ponto de vista", na tessitura do evento discursivo - de uma maneira mais deliberada do que no caso de metáforas conceptuais, que são de natureza fundamentalmente inconsciente. A análise dos exemplos, retirados de corpora autênticos, aponta para a conclusão de que o processo de "realçar" e "esconder" elementos do domínio-fonte, típico tanto da metáfora quanto da analogia, é usado como um recurso, de natureza cognitivo-discursiva, que se mostra determinante tanto para a construção do objeto do discurso, quanto para sua recepção.

Palavras-chave: Metáfora. Ideologia. Cognição. Argumentação.
\end{abstract}

\section{Introdução}

Desde a ruptura da visão da metáfora como figura de linguagem, com uma função essencialmente secundária - ou "ornamental" - no processo de construção de sentidos, e da consequente introdução do que hoje é conhecido como o "paradigma cognitivista", promovido por Lakoff e Johnson em Metaphors we live by (1980), a metáfora vem adquirindo contornos conceituais cada vez mais diversificados, refinados e, consequentemente, complexos. Com isso, o debate

* Professora Titular do Departamento de Letras Estrangeiras Modernas e do Programa de Pós-Graduação em Estudos de Linguagem da Universidade Federal Fluminense (UFF). 
em torno do conceito de metáfora vem, também, se ampliando, alcançado vários domínios do conhecimento e revelando, assim, a multidisciplinaridade dos estudos nesse campo.

Evidência dessa abrangência pode ser encontrada no conjunto de temas propostos para a conferência do $11^{\circ} \mathrm{RaAM}$ (Researching and Applying Metaphor), principal evento internacional na área da metáfora, que aconteceu em Berlim, em julho de 2016, ou seja, 36 anos após o lançamento da obra seminal de Lakoff e Johnson:

- Metaphor and aesthetics

- Metaphor and affect

- Metaphor and embodiment

- Perceiving and understanding metaphor

- Metaphoric meaning making

- Narrativity, figuration and metaphor

- Metaphor and expression

- Metaphor and representation

- Metaphor and temporality

- Actions, applications and metaphor

- Metaphor and creativity

- Multimodal metaphor

- Conceptual metaphor in media and the arts

Muitos desses temas podem ser vistos como desdobramentos da Teoria da Metáfora Conceptual (TMC), ou, pelo menos, poderiam ser considerados teórica e analiticamente compatíveis com essa teoria, já tendo sido, inclusive, explorados por pesquisadores a partir da perspectiva cognitivista. No entanto, a TMC, em sua tendência mais ortodoxa, por deslocar o lócus da metáfora da linguagem para o pensamento, passou a negligenciar aspectos do funcionamento da metáfora no âmbito discursivo. Afinal, na visão clássica, a linguagem em uso seria apenas o cenário no qual as representações cognitivas, como as metáforas conceptuais, frames (FILLMORE, 2006) e Modelos Cognitivos Idealizados - MCIs (LAKOFF, 1987), por exemplo, seriam evocadas ou instanciadas.

Nos últimos anos, a relevância de se investigar a metáfora na linguagem em uso tem sido ressaltada, sendo que o grande desafio dessa investida é conciliar 
cognição e discurso (linguagem em uso) e, principalmente, explorar a relação entre esses dois domínios, de modo algum dicotômicos, mas sim complementares. Para exemplificar essa tendência a partir, mais uma vez, de temas trabalhados em eventos científicos na área, as mesas plenárias do VI Congresso da Metáfora na Linguagem e no Pensamento, que aconteceu na Universidade Federal de Minas Gerais, em Belo Horizonte, em 2015, tiveram como títulos:

- Metaphor and discourse (Prof. Gerard Steen)

- Metaphor and gestures (Profa. Cornelia Müller)

- Metaphor in language teaching (Profa. Jeannete Littlemore)

- Metaphor impairment (Profa. Maity Siqueira)

Ou seja, esses temas parecem estar direcionados, a partir de ângulos diferentes, a aspectos da metáfora no âmbito do discurso em funcionamento e não apenas do sistema conceptual. O desafio de se abordar a metáfora na recente vertente cognitivo-discursiva é, principalmente, o de buscar possíveis articulações entre os aspectos da cognição característicos do sistema conceptual (cognição estável "e") e aqueles típicos do acontecimento discursivo (cognição episódica/emergente “e”"). O quadro abaixo (FIG. 1), apresentado por Vereza (2013), resume algumas dessas possíveis articulações, que participam do funcionamento da metáfora na linguagem em uso.

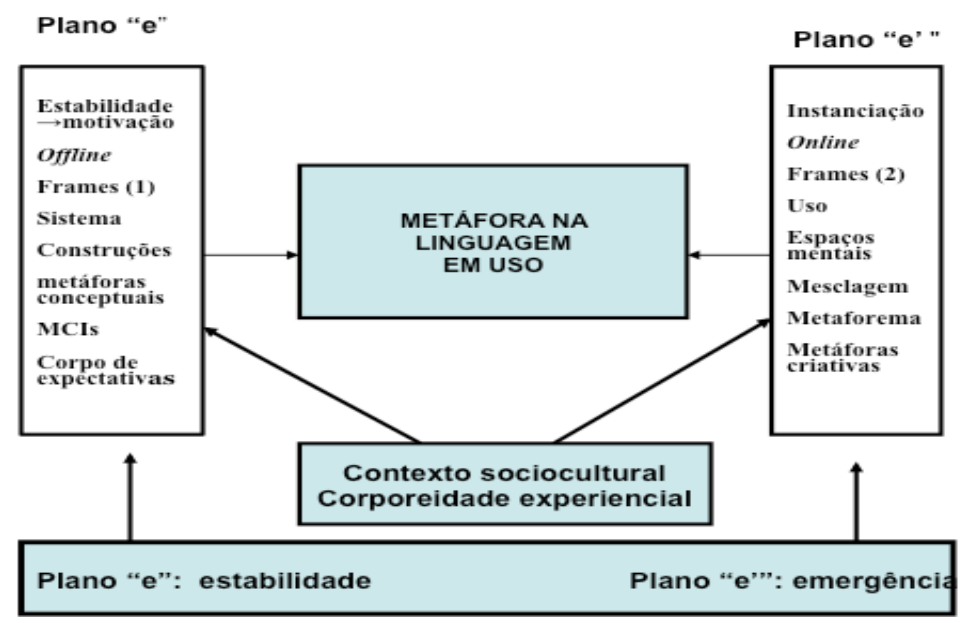

FIGURA 1 - Dinâmica da metáfora em uso Fonte: Vereza, 2013. 
Nesse quadro, um dos aspectos ressaltados para a articulação proposta, juntamente com a corporeidade experiencial, um dos conceitos pilares da linguística cognitiva, é o contexto sociocultural em que se dá o evento discursivo. Lakoff e Johnson, já em Metaphors we live by, ressaltavam, por um lado, o papel da cultura na formação das representações e, portanto, da metáfora conceptual, no nosso sistema cognitivo e, por outro, o papel dessas mesmas representações na formação da cultura. A relação entre cultura e metáfora foi amplamente discutida por Kövecses (2005), que tratou da questão da universalidade de metáforas conceptuais vis-à-vis dos possíveis efeitos da cultura em sua diversidade. Se partimos do pressuposto de que tanto a cultura quanto a ideologia são, em grande parte, responsáveis pelo que se pode chamar visões de mundo (UNDERHILL, 2013), não podemos tratá-las como instâncias claramente dicotomizáveis na construção sociocognitiva dos sentidos.

Sendo assim, o contexto sociocultural, indicado no quadro acima, acolhe tanto aspectos culturais quanto ideológicos, se é que se pode distinguir esses dois aspectos com alguma precisão. De qualquer forma, a dimensão mais nitidamente ideológica da metáfora, principalmente no que se refere à presença de linguagem metafórica em discursos políticos (o que seria, no senso comum, conceitual e operacionalmente mais ideológico do que cultural) foi objeto de várias pesquisas que vêm formando, em seu conjunto, uma área já conhecida como Teoria Crítica da Metáfora (CHARTERIS-BLACK, 2004; MUSSOLF, 2004; GOATLY, 2007; UNDERHILL, 2013).

Dentro dessa perspectiva, o objetivo deste artigo é explorar a dimensão ideológica da metáfora, mas no que se refere a seu uso no discurso, no nível "e"”, ou episódico, online, em contrapartida ao nível "e", o âmbito das representações mais estáveis, offline. Como veremos na seção a seguir, a ideologia, no nível episódico, será abordada, neste trabalho, com um determinado viés argumentativo a ser caracterizado como um tipo de "argumentação via analogia" (TINDALE, 2008), a ser tecida discursiva e cognitivamente pela linguagem metafórica. Nessa tessitura, procuraremos mostrar como o processo de "realçar e encobrir" (highlighting e hiding), característico do mapeamento metafórico (LAKOFF; JOHNSON, 1980, 2002) e de grande parte das relações analógicas como um todo, concorrem para o estabelecimento da argumentatividade de um texto. Ocorrências do uso argumentativo da metáfora, que ilustrarão a discussão, serão retiradas de corpora autênticos, conferindo maior legitimidade às conclusões propostas do que no caso de exemplos "inventados" (GIBBS, 1999). 


\section{Metáfora, argumentação e a questão da consciência/deliberalidade}

Os estudos clássicos que têm como foco a metáfora conceptual passaram, recentemente, a dividir a pesquisa na área com aqueles que caracterizam a chamada "virada cognitivo-discursiva". Esses últimos, seguindo a proposta de Gibbs (1999, p. 145) de "tirar a metáfora fora de nossas cabeças e colocá-la no mundo cultural", o discurso aqui incluído, passam a contemplar aspectos do funcionamento da metáfora no evento discursivo (SEMINO, 2008). Assim, questões relativas à metáfora em uso, e não apenas à metáfora no sistema (STEEN, 2006), passam a merecer a atenção de pesquisadores na área, que propõem novos conceitos e unidades de análise para se investigar a metáfora a partir desse novo prisma. Nesse sentido, Cameron e Deignan (2006) propuseram a noção de metaforema; Oswald e Rihs (2013), de metáfora estendida; Cameron e Maslen (2010), de metáfora sistemática; Zinken (2007), de metáfora discursiva, e Vereza (2007, 2013), de metáfora situada e nicho metafórico.

Tratar a dimensão ideológica da metáfora em uso desloca o foco da pesquisa da metáfora conceptual para a metáfora no uso linguístico, ou, pelo menos, para as instanciações da metáfora conceptual na linguagem e seus efeitos ideológicos no discurso. Esses efeitos, do ponto de vista do evento discursivo, podem ser abordados teórica e analiticamente como argumentatividade: uma visão de mundo no nível do sistema passa a ser tratada como um ponto de vista tecido na rede discursiva. Ou seja, a metáfora em uso (em suas diversas formas: sistemática, situada, estendida e em nichos metafóricos) pode determinar uma dada "orientação argumentativa”, que, segundo Guimarães (2013, p. 271) é “a apresentação pelo locutor para seu alocutário de uma relação de sentidos que orienta a direção do dizer, considerada como necessária".

Um exemplo (1) dessa orientação argumentativa seria o breve nicho metafórico:

$(1)^{1}$ Com o afundamento do governo, o PMDB abandona provisoriamente os cargos para retomá-los mais tarde em melhores condições. Os ratos abandonam o navio, mas mantém uma das patinhas no convés pra pular de volta.

O nicho em (1) evoca um cenário metafórico em que dois frames, de uma certa forma convencionais, são acionados: o do navio afundando (um frame muito comum

1 Disponível em: <http://www.pstu.org.br/node/22002>. Acesso em: 30 mar. 2016. 
para se referir a situações, instituições, relações, etc., avaliados como estando em processo de declínio), um provável desdobramento da metáfora conceptual A VIDA É UMA VIAGEM DE BARCO/NAVIO, e, a partir deste, o de ratos abandonando o navio (metáfora primária SITUAÇÃo É RECIPIENTE). Pela avaliatividade negativa do domínio-fonte "rato", associada ao abandono (concebido como "traição") destes de uma situação difícil, a orientação argumentativa traça claramente um perfil bastante negativo dos políticos do partido em questão. A metáfora situada (políticos do PMDB são ratos abandonando um navio), de natureza episódica, apoia-se em frames estáveis e em metáforas conceptuais para traçar a orientação pretendida.

Nesse sentido, a metáfora se reveste de uma função argumentativa reconhecida desde a Antiguidade. Segundo Oswald e Rihs (2013, p. 25),

a metáfora é considerada, desde há muito tempo, um recurso retórico que atende a funções estratégicas em interações argumentativas. Assim como muitas figuras retóricas, acredita-se que ela seja especialmente eficiente, às vezes, mais do que construções literais, quando se trata de convencer o público. ${ }^{2}$

Em sua função retórica ou argumentativa, não se pode afirmar que a metáfora no discurso, ao contrário da metáfora conceptual, seja de fato inconsciente. E é nesse sentido que creio ser necessário distinguir a ideologia característica das representações cognitivas, que formam o sistema conceptual, e, portanto, uma visão de mundo, da orientação argumentativa, que constrói o objeto de discurso a partir da exploração textual de um determinado ponto de vista, de uma certa forma intencionado.

A questão da consciência, intencionalidade e/ou deliberalidade da metáfora na produção discursiva é objeto de polêmica entre estudiosos (DEIGNAN, 2011; GIBBS, 2011; STEEN, 2011). Parece haver, no entanto, algum consenso quanto ao grau de reconhecimento da metáfora no uso discursivo, principalmente no que se refere a sua convencionalidade (quanto mais convencional, menos deliberada/ intencional/consciente a metáfora seria) e a seu uso em determinados gêneros (DIENSTBACH, 2015), que acolheriam em maior ou menor grau a linguagem

2 [Metaphors have long been considered to function as rhetorical devices fulfilling strategic goals in argumentative exchanges. As many rhetorical figures, they are believed to be particularly effective, sometimes more than literal formulations, when it comes to convincing an audience.]. (Tradução da autora.) 
metafórica. Nesse sentido, a presente pesquisa alinha-se à visão de Müller (2008) de que não haveria, na metáfora em si, elementos semânticos que a tornariam, por exemplo, "nova" ou "morta", mas que o seu uso no discurso poderia reativar, por exemplo, a metaforicidade 3 a princípio dada como nula, "acordando", assim, a "metáfora adormecida", para usar a expressão proposta pela própria pesquisadora. Podemos pensar em uma metáfora altamente convencionalizada, cuja metaforicidade pode ser reativada num jogo discursivo, como nos exemplos (2) e (3) retirados de blogs.

$(2)^{4}$ É tão cara de pau que quando faz a barba não cai cabelo... cai serragem.

(3) $)^{5}$ Putz, estou morto... Muito trabalho... Consertando as mancadas dos outros... Mas a adrenalina te ressuscita... Te acorda...

A intencionalidade ou deliberalidade, particularmente no exemplo (2), parece bastante clara, principalmente pelo reconhecimento do propósito humorístico do enunciado em questão, efetivado por um jogo analógico com a metáfora "cara de pau": se quando se faz a barba em uma cara normal, cai pelo ou cabelo, em uma cara de pau (portanto, de madeira), o que cai é serragem. A analogia "acorda" a metáfora adormecida "cara de pau", que tem sua metaforicidade reativada no jogo discursivo. Em (3), o propósito não parece ser de humor, mas de intensificação ou ênfase do estado físico referido; ou seja, uma hiperbolização do estado de cansaço. A hipérbole metafórica em "morto" ("estou morto de cansaço") já parece ter se convencionalizado de tal forma que provavelmente não alcança o efeito de intensificação pretendido (MIRANDA, 2009). O jogo com a expressão "adrenalina te ressuscita" de certa forma "ressuscita", também, a metaforicidade de "estou morto".

Outra forma de reativar a metáfora é por meio de linguagem multimodal (FORCEVILLE; URIOS-APARISI, 2009). É comum haver esse jogo discursivo, em que a metáfora é metadiscursivamente reativada (e "desconstruída") em gêneros como capas de revista, como a da FIG. 2. Nesse caso, a metáfora primária

3 Metaforicidade consiste na possibilidade de uma expressão metafórica ser reconhecida como tal, cuja determinação depende de propriedades que caracterizam o evento discursivo em que essa expressão ocorre (DIENSTBACH, 2015).

4 Diponível em: <http://www.osvigaristas.com.br/frases/231615.html>. Acesso em: 15 mar. 2016.

5 Disponível em: <http://naoepsicosenaoe.blogspot.com.br/2012/01/cansaco-mesmo.html>. Acesso em: 15 mar. 2016. 
DIFICULADE É PESO, que licencia expressões corriqueiras como "sinto um enorme peso da responsabilidade que colocaram sobre mim" e "o executivo paulista vai tirar um peso dos ombros (ambas retiradas de um site de busca), normalmente usadas em contextos que não necessariamente realçam sua metaforicidade, é reativada por meio da imagem, que, de alguma forma "literaliza" a metáfora. Esse jogo discursivo hiperboliza o argumento, que aponta para as dificuldades do governo prestes a assumir na ocasião, além de promover a conceptualização da presença do estado na economia como um "peso", ou seja, algo a ser evitado. Dessa forma, o ponto de vista é tecido pelo entrelace entre metáforas conceptuais, frames, e as metáforas situadas no texto: "o estado é um peso para o governo". Interessante observar que o governo também é conceptualizado, metonimicamente, com um homem, que, do ponto de vista do gênero, também reforça uma ideologia sexista, talvez de uma forma não tão consciente quanto aquela relativa ao papel do estado.

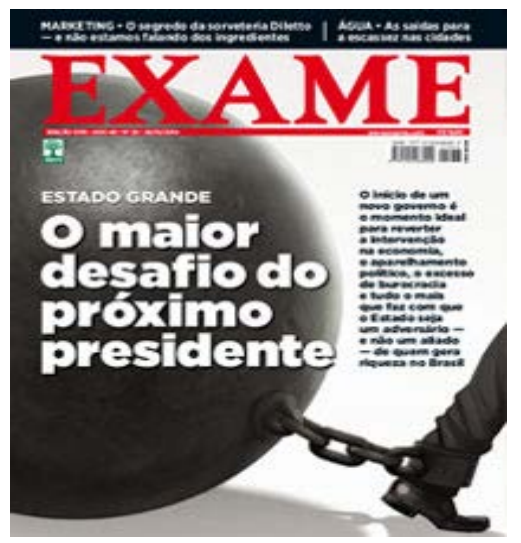

FIGURA 2 - Reativando metáforas em capas de revista Fonte: <https://bigfull.wordpress.com/2014/03/13/engolindo-sapo/>. Acesso em: 2 mar. 2016.

Assim, um estudo sobre o papel argumentativo da metáfora e, como veremos mais adiante, da analogia em geral, na linguagem em uso, deve considerar que o uso desses dois recursos cognitivo-discursivos pressupõe um certo grau de intencionalidade e, portanto, de consciência. "Acordar" uma metáfora, estendê-la em nichos metafóricos, construir o objeto de discurso por meio de mapeamentos ou analogias ou até mesmo "desconstruir" um provérbio ("devagar é que não se 
vai longe": como o fez o compositor Chico Buarque, na canção Bom Conselho) requerem uma postura metadiscursiva, que necessariamente se reveste de, pelo menos, algum grau de deliberalidade.

\section{Realçar e encobrir como estratégias cognitivas na argumentação}

Lakoff e Johnson dedicam um capítulo de sua obra Metaphors we live by para descrever o processo que promove a sistematicidade da metáfora, pelo qual compreendemos um conceito em termos de outro. Esse processo implica mapear ou projetar um (ou alguns) - e não todos - os elemento(s) de um domínio (o domínio-fonte: source domain) sobre o outro (o domínio-alvo: target domain), sendo esse elemento realçado no processo. Dessa forma, os outros elementos não mapeados são encobertos na projeção metafórica. O mapeamento é, portanto, sempre parcial, realçando determinados elementos e não outros; "se fosse total, um conceito seria, de fato, o outro e não simplesmente entendido em termos de outro" (2002, p. 57).

Esse mesmo processo de realçar e encobrir acontece na dinâmica da metáfora em uso, com a diferença de que a consciência ou deliberalidade do mapeamento e dos elementos projetados parece, em muitos casos, ser bem maior. Não apenas podemos nos dar conta, mais facilmente, do mapeamento e do processo de realçar e encobrir que dele faz parte, mas também usar, com frequência, esse processo para fins argumentativos.

Tindale (2008) concebe o "argumento por analogia", que, acreditamos, incluiria o argumento tecido pela exploração da metáfora em uso (situada, sistemática ou em nicho), como uma importante e frequente estratégia no estabelecimento da orientação argumentativa de um enunciado. O que propomos aqui é que parte importante dessa estratégia se ancora nos mapeamentos cognitivo-discursivos, de natureza episódica (online), textualmente desenvolvidos.

Após a introdução do paradigma cognitivista da metáfora, acredita-se que tanto a metáfora quanto a analogia não pressuponham, necessariamente, uma similaridade a priori entre os domínios. A similaridade seria estabelecida pelo próprio mapeamento, a partir do realce de determinados elementos dos domínios envolvidos. Em uma metáfora como "Hugo é um trator", esse elemento, na maior parte dos contextos, seria a força do trator e/ou sua eficiência em derrubar obstáculos, e não o fato de o trator ser usado para obras em estradas ou no meio 
rural, ter rodas grandes, ser normalmente amarelo ou lento. O mapeamento cria a semelhança, mas apenas entre os elementos que são realçados, a partir da relevância no contexto discursivo (SPERBER; WILSON, 2012). Essa mesma relevância não se aplicaria aos outros elementos dos domínios envolvidos. No jogo discursivo, no entanto, esse mapeamento pode ser "desconstruído", para fins humorísticos, por exemplo, para que surja um possível enunciado como "Hugo é mesmo como um trator: eficiente, mas com muito pouca agilidade". A metáfora adormecida é reativada para fins avaliativos/humorísticos a partir do "descobrimento" de um elemento que normalmente é encoberto (a lentidão do trator).

A proposta aqui apresentada acerca dos efeitos argumentativos do processo de realçar e encobrir será ilustrada, na seção a seguir, com alguns episódios noticiados na imprensa brasileira e algumas de suas repercussões discursivas.

\section{Efeitos cognitivo-discursivos do processo de realçar e encobrir: alguns exemplos}

O primeiro exemplo trata de uma declaração do ex-governador do Rio de Janeiro, Anthony Garotinho, envolvendo a Presidente Dilma Rousseff. O excerto da reportagem publicada no website Terra Magazine, exemplo (4), não só descreve brevemente o episódio, mas também o avalia criticamente:

$(4)^{6}$ Questionado sobre os bons índices de popularidade da presidente, Garotinho respondeu: "Hitler também era (popular)". Com a intenção de contribuir para com a formação, digamos, intelectual, do deputado, vamos tentar explicar a ele por que se se pode comparar Hitler com alguma coisa, isso jamais seria possível ser feito com relação à nossa presidente. Por exemplo, deputado, Dilma é uma mulher humanista, democrata, e culta. Ela seguramente é uma pessoa de convicções, mas soube trocar as que talvez tivesse aos 19 anos por teses mais de acordo com as ideias libertárias que foram se impondo ao longo do século 20 . Hitler nunca mudou, nunca deixou de acreditar no que acreditava, por mais insano e insensato que fosse, no que se parece sabe com quem, deputado? A popularidade de Dilma e de Hitler vem de origens absolutamente distintas e inversas. A origem da popularidade de Hitler não pode ser comparada com a de Dilma, mas pode sim

6 Disponível em: <http://terramagazine.terra.com.br/interna/0,,OI5617681-EI8423,00Dilma+e+Hitler. html>. Acesso em: 12 abr. 2016. 
ser comparada sabe com qual tipo de popularidade, estimado deputado Garotinho? Ora, com a sua!

A analogia efetuada pelo ex-governador parece realçar um elemento do domínio-fonte "Hitler", a ser mapeado para o domínio-alvo "Dilma Rousseff". No entanto, o contexto parece evidenciar o realce em apenas um elemento do domínio "Hitler": a sua popularidade, que seria projetada para a popularidade do domínio-alvo: a popularidade de Dilma Rousseff. No entanto, a natureza do mapeamento é claramente argumentativa: a escolha de "Hitler" como fonte de popularidade não pode ser ignorada. Pelo frame que o conceito "Hitler" evoca sociocognitivamente, é praticamente impossível encobrir outros elementos como: autoritarismo, falta de humanidade, tirania, sadismo, etc., que "saltam à mente" quando o nome do ditador é evocado. Sendo assim, o jornalista rechaça a analogia por considerar a Presidente Dilma uma mulher "humanista, democrata, e culta", não podendo, portanto, ser comparada a Hitler, mesmo se o fosse apenas pela sua popularidade, pois "a popularidade de Dilma e de Hitler viriam de origens absolutamente distintas". Ao inverter o domínio-alvo, trocando a presidente pelo ex-governador como alvo da projeção, o jornalista não apenas evoca a popularidade de Anthony Garotinho, mas a origem dessa popularidade, que, nessa "contra-analogia", seria semelhante à de Hitler. Essa semelhança é, da mesma forma, criada pela própria analogia e é sustentada pela tessitura da orientação argumentativa.

Análise semelhante pode ser feita a partir do exemplo (5)

$(5)^{7}$ Megan Fox comparou as atitudes do diretor Michael Bay ao comportamento do ditador alemão Adolf Hitler. Parte da equipe do filme rebateu as críticas da atriz em carta divulgada pelo site Just Jared. "Ela disse que ele é um Hitler. Ela não deve saber o que é ter um Hitler em seu caminho. Ele é sério e exigente, mas sabe ser divertido também", diz um trecho do texto.

Nesse exemplo, podemos ver, mais uma vez, que o uso de "Hitler" como conceito-fonte dificilmente permite o encobrimento de vários elementos pertencentes ao domínio em questão. Seria possível que a atriz estivesse apenas realçando o elemento "autoritarismo", de uma forma hiperbólica (VEREZA, 2016),

7 Disponível em: <http://ego.globo.com/Gente/Noticias/0,,MUL1306389-9798,00-EQUIPE+DE+ TRANSFORMERS+DETONA+MEGAN+FOX+SERIA+A+NOVA+ANGELINA+MAS+NAO+E. html>. Acesso em: 13 abr. 2016. 
como é o caso de muitas metáforas discursivas (até mesmo a do "trator", analisada acima, pois dificilmente alguém teria a força de um trator), mas a intensidade cognitiva dos outros elementos do frame não permite que sejam encobertos.

É difícil se prender a elementos isolados de um domínio-fonte constituído de um frame com a força sociocognitiva e ideológica de um "Hitler". O mesmo parece acontecer no uso analógico do domínio-fonte "Cristo". Os comentários que seguem à notícia, no exemplo (6), evidenciam a quase impossibilidade de se mapear discursivamente aspectos específicos do frame "Cristo", sem que se projetem também outros elementos considerados socioculturalmente essenciais e, portanto, muito difíceis de serem encobertos:

$(6)^{8}$ Temer diz que Levy deve ser tratado como 'Cristo' após ajuste fiscal.

- Ah então vamos dar a ele o sofrimento da via crucis que Jesus passou.

- Eu não reconheço este cidadão como Cristo. Ninguém nesta terra chega ao Salvador,

- Será que o Temer sabe que Cristo foi crucificado? Esse Levy tá mais pra Pilatos, porque está crucificando o povo brasileiro.

- A que ponto chegamos, comparar um cidadão com Jesus Cristo.

- Na face da terra, e pelo que foi escrito sobre Jesus Cristo, não há um ser humano que possa equipará-lo!

- Pois então vamos pregá-lo na cruz....

- Esse Michel Temer é um profanador comparar Joaquim Levi a Jesus Cristo, Jesus Cristo é Santo, Joaquim Levi um ímpio que está roubando o povo brasileiro.

Evocar o frame de "Cristo" como fonte de analogia é um ato retórico sempre arriscado, no caso de não se explicitar, no desenvolvimento argumentativo, que elementos específicos estão sendo projetados. Quando não há tal explicitação, a projeção evocada não vai ser sempre a mais prototípica, socioculturalmente definida. No caso de "Cristo", os elementos desse frame prototípico, evidenciados nos comentários, parecem ser aqueles relativos ao sagrado e à salvação ("não há um ser humano que possa equipará-lo"; "Ninguém nesta terra chega ao Salvador"), ao sofrimento ("Ah então vamos dar a ele o sofrimento da via crucis que Jesus

8 Disponível em: <http://g1.globo.com/politica/noticia/2015/06/temer-diz-que-levy-deve-ser-tratadocomo-cristo-apos-ajuste-fiscal.html $>$. Acesso em: 14 abr. 2016. Todos os comentários usados no exemplo seguem, entre muitos outros de natureza crítica semelhante, a notícia dessa página. 
passou"), à misericórdia e ao amor divino ao próximo ("Jesus Cristo é Santo"). Encobrir esses elementos do frame pode ser visto como um ato de heresia; uma blasfêmia.

Vale ressaltar também a avaliatividade do domínio-alvo. De uma maneira geral, em nosso país, políticos não gozam de uma reputação particularmente positiva e, por contiguidade, ministros tendem também a ser vistos com uma certa desconfiança. Portanto, um ministro (no caso, Levy) não poderia, para muitos, ser comparado a Cristo e, consequentemente, quem produz a analogia (um político, Temer), a fonte da heresia, é o maior alvo das críticas.

Um outro exemplo, tendo também como domínio-fonte "Cristo", seria um trecho de um discurso do ex-presidente Luiz Inácio Lula da Silva em (7), em que ele se defendia de acusações da Justiça Federal, em uma assembleia formada por muitos apoiadores:

$(7)^{9} \mathrm{Eu}$ falo para o meu filho: Não fica com raiva. É assim, meu filho. Vamos suportar. Jesus Cristo sofreu mais do que nós.

Essa analogia parece realçar o elemento "sofrimento" do domínio-fonte "Jesus Cristo", a ser projetado no elemento "sofrimento de Lula e daqueles que o apoiam". Novamente, a analogia hiperboliza o sofrimento, mas usar o frame de "Cristo" implica a ativação cognitiva dos outros elementos socioculturalmente relevantes do frame. A reação de muitos cristãos seria provavelmente de indignação, como nos comentários em (8):

- É verdade o que o Lula tá falando em relação as suas comparações com Jesus, ele deve tá sofrendo muito, visto que $70 \%$ do país que era a seu favor e se virou contra ele. Porém ele se esqueceu de um detalhe mínimo, quase imperceptível, Jesus era inocente e sem pecados que sofreu muito até a crucificação e não merecia nenhuma acusação a qual foi submetido.

- Qualquer comentário somente daria vazão para mais blasfêmias. Pobre alma em trevas... Me lembra Simão (Atos 8) e Herodes (Atos 11).

9 Trecho do discurso e comentários em (8) disponíveis em: <https://noticias.gospelprime.com.br/ acuado-investigacoes-lula-compara-jesus $>$. Acesso em: 15 mar. 2016. 
O "detalhe mínimo" mencionado no primeiro comentário se refere a um elemento cuja projeção não foi intencionada (Lula provavelmente não estava se referindo a sua "falta de pecados"), mas analogias com "Cristo" correm sempre o risco de serem avaliadas como "blasfêmias" (como no segundo comentário), principalmente quando o domínio-alvo goza de uma avaliação não consensualmente positiva. Mas qualquer pessoa que se compara deliberadamente a Cristo, mesmo que o elemento da projeção seja pontual, e não necessariamente relacionado ao sagrado, pode sofrer, em princípio, o mesmo tipo de reação negativa do interlocutor, principalmente se este compartilhar a fé em questão, que pode ser vista como uma ideologia religiosa ou "espiritual" (analogia esta que também corre o risco de ser interpretada, pelas mesmas razões aqui descritas, como "espiritualmente inadequada").

Portanto, como no caso do uso do frame "Hitler" como fonte da analogia e base da orientação argumentativa, o frame "Cristo" praticamente impede a seletividade do elemento a ser realçado: normalmente, haverá, no mapeamento, outras projeções além das intencionadas.

\section{Considerações finais}

Neste artigo procuramos elaborar a proposta de que a dimensão ideológica da metáfora pode ser tratada a partir de duas perspectivas. A primeira tem como foco os aspectos e efeitos ideológicos de metáforas conceptuais como representações sociocognitivas em nível de sistema, tanto conceptual quanto linguístico. Nessa dimensão, metáforas conceptuais como NAÇão É FAMílIA e ESTADO É PAI, por exemplo, são vistas como participantes da construção de uma "visão de mundo" que determina a maneira pela qual conceptualizamos vários aspectos da realidade. A Teoria Crítica da Metáfora agrega muitas pesquisas (CHARTERIS-BLACK, 2004; MUSSOLF, 2004; GOATLY, 2007; UNDERHILL, 2013) que têm essas questões como perspectiva norteadora, utilizando-se, com frequência, de discursos políticos como corpora principais, justamente por sua natureza ideológica.

A segunda dimensão estaria no âmbito da linguagem e da cognição em uso, e não no sistema, apesar de haver uma articulação sistemática entre esses dois níveis. A pesquisa com foco na metáfora em uso, como a proposta neste trabalho, trata a ideologia como uma orientação argumentativa, ou argumentatividade, ou seja, um ponto de vista a ser desenvolvido cognitivo-discursivamente por meio de mapeamentos locais, na tessitura do evento discursivo. 
Os mapeamentos locais podem tomar a forma de metáforas situadas, sistemáticas, estendidas ou de nichos metafóricos. O que esses mapeamentos têm em comum com os mapeamentos estabelecidos no nível do sistema, apesar de sua natureza mais deliberada e, portanto, consciente, é o processo de "realçar e encobrir" determinados elementos de um dado domínio-fonte e encobrir outros. O que procuramos mostrar, a partir da discussão de vários exemplos, é que esse processo, no evento discursivo, tem efeitos argumentativos claros, já que não podemos partir de semelhanças a priori entre os domínios envolvidos na projeção. Muitas vezes, em textos argumentativos, o elemento que se pretende realçar é acompanhado por outros elementos, cujo realce não era intencionado, causando, na recepção, efeitos argumentativos também não esperados.

Não se pretendeu, aqui, estabelecer uma dicotomia entre a dimensão do sistema (linguístico e cognitivo) e a do uso no ato discursivo, mas, para efeitos teóricoanalíticos, essas duas dimensões devem ser consideradas, para que possamos definir mais adequadamente nosso objeto de pesquisa, direcionar nossas perguntas, definir metodologias e, inclusive, trazer luz sobre a articulação entre elas. Afinal, cada mapeamento situado pressupõe a evocação de representações como frames e metáforas conceptuais, da mesma forma que cada orientação argumentativa pressupõe orientações ideológicas mais estáveis e menos accessíveis à consciência. Investigar a complexidade desse entrelace é um grande desafio para a linguística cognitiva contemporânea e, ao propormos ferramentas teórico-analíticas que possam participar, mesmo que exploratória e tentativamente, desse desafio, acreditamos estar contribuindo, de uma alguma forma, se não para responder, mas para levantar novas perguntas. 


\title{
The argumentative effects of metaphor and analogy from a cognitive-discursive perspective
}

\begin{abstract}
The overall aim of this article is to discuss the ideological effects of metaphor in the production of meaning, from the perspective of Cognitive Linguistics, an area already largely consolidated within language studies. More specifically, the focus lies on the way that ideology can be approached theoretically and analytically, within the new tendency, in metaphor research, which investigates the relationship between the cognitive and the discursive dimensions of figurative language in use. The argument proposed, which is discussed theoretically and illustrated with examples from authentic corpora, is that metaphor, like analogy, constructs "argumentativity", which could be seen as the way through which ideology is configured as a "point of view" in the discourse event, more deliberately that in the case of conceptual metaphors, which are essentially unconscious. In this argumentative orientation, the process of highlighting and hiding, typical of metaphor and analogy, is used as a cognitive and discursive resource, which is determinant for the construal of the discourse object as well as for its reception.
\end{abstract}

Keywords: Metaphor. Ideology. Cognition. Argumentation.

\section{Referências}

CAMERON, Lynne; DEIGNAN, Alice. The emergence of metaphor in discourse. Applied Linguistics, v. 27, n. 4, p. 671-690, 2006.

CAMERON, Lynne; MASLEN, Robert (Org.). Metaphor analysis: research practice in applied linguistics, social sciences and the humanities. Londres: Equinox, 2010.

CHARTERIS-BLACK, Jonathan. Corpus approaches to critical metaphor analysis. New York: Palgrave, 2004.

DEIGNAN, Alice. Deliberateness is not unique to metaphor: a response to Gibbs. Metaphor and the Social World, v. 1, n. 1, p. 57-60, 2011.

DIENSTBACH, Dalby. Metaforicidade como um aspecto do gênero: uma abordagem cognitivo-discursiva para a reconhecibilidade das metáforas. In: Caderno de Resumos do VI Congresso da Metáfora na Linguagem e no Pensamento. Belo Horizonte: UFMG, 2015. p. 35.

FILLMORE, Charles. Frame semantics. In: GEERAERTS, Dirk. Cognitive Linguistics: basic readings. Berlim: Mouton de Gruyter, 2006, p. 373-400. 
FORCEVILLE, Charles; URIUS-APARISI, Eduardo (Org.). Multimodal metaphor. Berlim/Nova York: Mouton de Gruyter, 2009.

GIBBS, Raymond. Taking metaphor out of our heads and putting it into the cultural world. In: GIBBS, Raymond; STEEN, Gerard. Metaphor in Cognitive Linguistics: selected papers from the 5th International Cognitive Linguistics Conference, Amsterdam, 1997. Amsterdam: John Benjamins, 1999. p. 145-159.

GIBBS, Raymond. Are 'deliberate' metaphors really deliberate? A question of human consciousness and action. Metaphor and the Social World, v. 1, n. 1, p. 26-52, 2011.

GOATLY, Andrew. Washing the brain: metaphor and hidden ideology. Amsterdam: John Benjamins, 2007.

GUIMARÃES, Eduardo. Argumentatividade e argumentação. Revista Desenredo, v. 9, n. 2, p. 271-283, 2013.

KÖVECSES, Zoltán. Metaphor and culture. Cambridge: Cambridge University Press, 2005.

LAKOFF, George. Women, fire, and dangerous things: what categories reveal about the mind. Chicago: The University of Chicago Press, 1987.

LAKOFF, George; JOHNSON, Mark. Metaphors we live by. Chicago: The University of Chicago Press, 1980.

LAKOFF, George; JOHNSON, Mark. Metáforas da vida cotidiana. Tradução do Grupo de Estudos da Indeterminação e da Metáfora. Campinas, SP: Mercado de Letras; PUC-SP, 2002. Original publicado em 1980.

MIRANDA, Neusa Salim. Construções gramaticais e metáfora. Revista Gragoatá, v. 14, n. 26, p. 61-80, 2009.

MÜLLER, Cornelia. Metaphors dead and alive, sleeping and waking: a dynamic view. Chicago: University of Chicago Press, 2008.

MUSSOLF, Andreas. Metaphor and political discourse: analogical reasoning in debates about Europe. London: Palgrave Macmillan, 2004.

OSWALD, Seve; RIHS, Alain. Metaphor as argument: rhetorical and epistemic advantages of extended metaphors. Argumentation, v. 28, n. 2, p. 133-159, 2013. SEMINO, Elena. Metaphor in discourse. Cambridge: Cambridge University Press, 2008. 
SILVA, Augusto Soares. Metáfora conceptual e ideologia: o caso do discurso das políticas de austeridade na imprensa portuguesa. Revista Investigações, v. 28, n. 2, p. 1-38, 2015.

SPERBER, Deirdre; WILSON, Dan. Meaning and Relevance. Cambridge: Cambridge University Press, 2012.

STEEN, Gerard. Metaphor in applied linguistics: four cognitive approaches. D.E.L.T.A. v. 22, n. especial, p. 21-44, 2006.

STEEN, Gerard. What does 'really deliberate' really mean? More thoughts on metaphor and consciousness. Metaphor and the Social World, v. 1, n. 1, p. 5356, 2011.

TINDALE, Christopher. Fallacies and argument appraisal. Cambridge: Cambridge University Press. 2008.

UNDERHILL, James. Creating worldviews: metaphor, ideology and language. Edinburgh: Edinburgh University Press, 2013.

VEREZA, Solange Coelho. Metáfora e argumentação: uma abordagem cognitivodiscursiva. Linguagem em (Dis)curso, v. 7, n. 3, p. 487-506, 2007.

VEREZA, Solange Coelho. Entrelaçando frames: a construção do sentido metafórico na linguagem em uso. Cadernos de Estudos Linguísticos, v. 55, n. 1, p. 108-124, 2013.

VEREZA, Solange Coelho. Cry me a river: metaphoric hyperboles in the interface between discourse and cognition. Revista Gragoatá, n. 40, p. 175-196, 2016.

ZINKEN, Jörg. Discourse metaphors: the link between figurative language and habitual analogies. Cognitive Linguistics. v. 18, n. 3, p. 445-466, 2007.

Recebido em 22/05/2016.

Aceito em 13/07/2016. 